\title{
COMPARISON OF DIFFERENT MODELING METHODS FOR PREDICTION OF PALLADIUM ADSORPTION ONTO WASTE ORANGE PEEL
}

\author{
Aysun ÖZKAN ${ }^{*}$, Şahin IŞIK² ${ }^{2}$ Zerrin GÜNKAYA ${ }^{1}$, Kemal ÖZKAN² ${ }^{2}$ Müfide BANAR ${ }^{1}$ \\ ${ }^{1}$ Eskişehir Technical University, Faculty of Engineering, Department of Environmental Engineering, Eskişehir, \\ Turkey \\ ${ }^{2}$ Eskişehir Osmangazi University, Faculty of Engineering and Architecture, Department of Computer \\ Engineering, Eskişehir, Turkey
}

\begin{tabular}{ll}
\hline Keywords & Abstract \\
\hline Adsorption, & The objective of this work was to evaluate the adsorption potential of waste orange \\
Curve Fitting, & peels for the removal of palladium. Among linear models, Langmuir isotherm model \\
Nonlinear Modeling, & was more suitable for the adsorption process. Adsorption kinetics analysis of \\
Palladium. & pseudo-second-order model revealed that intraparticle transport was not the only \\
& rate-limiting step. Analysis based on the nonlinear mathematical modeling indicated \\
& that Smoothing Spline model shows best fitting with higher R-square $\left(\mathrm{R}^{2}\right.$ ) and lower \\
Sum of Square Error (SSE) and Root Mean Square Error (RMSE). It was concluded \\
that the SSE and RMSE values should be taking into account as well as $\mathrm{R}^{2}$ in the \\
adsorption studies.
\end{tabular}

\section{ATIK PORTAKAL KABUKLARI ÜZERINE PALADYUM ADSORPSIYONU IÇCiN FARKLI MODELLEME YÖNTEMLERININN KARŞILAŞTIRILMASI}

\section{Anahtar Kelimeler Adsorpsiyon, Eğri Uydurma, Nonlineer Modelleme, Paladyum.}

\begin{abstract}
Öz
$\mathrm{Bu}$ çalışmanın amacı, paladyumun giderimi için atık portakal kabuklarının adsorpsiyon potansiyelini değerlendirmektir. Doğrusal modeller arasında Langmuir izoterm modeli adsorpsiyon prosesi için en uygun olarak belirlenmiştir. Yalancı ikinci dereceden modelin adsorpsiyon kinetik analizi, partikül içi taşınmanın tek hız sınırlayıcı adım olmadığını ortaya koymuştur. Doğrusal olmayan matematiksel modellemeye göre, Yumuşatılmıș Spline modeli daha yüksek $\mathrm{R}^{2}$ ve daha düșük Toplam Kare Hatası (SSE) ve Kök Ortalama Kare Hatası (RMSE) ile en uygun model olmuştur. Adsorpsiyon çalıșmalarında $\mathrm{R}^{2}$ 'nin yanı sıra, SSE ve RMSE değerlerinin de dikkate alınması gerektiği sonucuna varılmıştır.
\end{abstract}

Alıntı / Cite

Özkan, A., Işık, Ş., Günkaya, Z., Özkan, K., Banar, M., (2021). Comparison of Different Modeling Methods for Prediction of Palladium Adsorption onto Waste Orange Peel, Journal of Engineering Sciences and Design, 9(3), 758-767.

Yazar Kimliği / Author ID (ORCID Number)

Makale Süreci / Article Process

A. Özkan, 0000-0003-1036-7570

Ş. Işık, 0000-0003-1768-7104

Z. Günkaya, 0000-0002-7553-9129

K. Özkan, 0000-0003-2252-2128

Başvuru Tarihi / Submission Date

Revizyon Tarihi / Revision Date

Kabul Tarihi / Accepted Date

23.03.2020

Yayım Tarihi / Published Date

31.03.2021

21.09.2021 


\section{Introduction}

Palladium (Pd) is an important precious metal and widely used for catalytic applications, electronic devices, plating materials, jewelry and pharmaceuticals (Morcali and Zeytuncu, 2015). The rapid industrial development resulting in the increasing demand for Pd has further enhanced the significance towards recovering this valuable metal. Techniques such as solvent extraction, ion exchange, chemical precipitation and adsorption are some of the well-known methods for the recovery of Pd (Sharma and Rajesh, 2016). Among them, adsorption is an effective strategy for the recovery of metal ions from aqueous solution and the selection of adsorbent plays a key role in it. Therefore, researches on novel adsorbents have attracted considerable attention in analytical ch emistry. Studies are also carried out on biosorbents such as tea waste (Öztürk et al., 2020); hazelnut processing plant wastes (Tunç Dede, 2019); banana peel (Fabre et al., 2020); lemongrass leaf (Putri et al., 2020); kiwifruit (Kızmaz et al., 2019).

In the literature, different adsorbents were used for Pd adsorption including, crosslinked lignophenol (Parajuli et al., 2009), chemical modified waste paper (Adhikari et al., 2008), modified polyacrylonitrile (Morcali and Zeytuncu, 2015), thiazole ligand tethered on an amine functionalized polymeric resin (Sharma and Rajesh, 2016), 1,3,5triazine-pentaethylenehexamine polymer (Sayın et al., 2015), polyamine functionalized polystyrene-based beads and nanofibers (Fayemi et al., 2013), 2-mercaptobenzothiazole impregnated cellulose (Sharma and Rajesh, 2014).

Mathematical modeling is an important and powerful tool that can be used regarding the identification of the limiting transfer mechanism. The model is validated through experimental data of the kinetics of sorption and allows the prediction of answers in many operational conditions, project design, optimization and control (Suzaki et al., 2017). Specifically, the curve fitting is one of the most used mathematical modeling tools by analyzing the relationship between the series of data points and representing the trend of them with a concise mathematical function. Depending on the subject, it can be used to estimate inner prediction (interpolation) or outer prediction (extrapolation). Usually, the curve fitting is utilized for interpolation as capturing the relationship between original variables and estimating the value of unknown inter variables that are located between original variables. Although there are different types of curve fitting, the least square curve fitting is a popular method among them. In the concept of least square curve fitting methodology, the sum of the square of error between original and estimated variables is minimized by taking the derivative of both sides of two equations. There are two types of curve fitting functions, namely, linear and nonlinear functions. In adsorption studies, in addition to linear models such as Langmuir, Freundlich and BET, various nonlinear mathematical models including Pseudo first order (Rathinam et al., 2010), Pseudo second order (Herrero et al., 2011), artificial neural network modeling (Yang et al., 2014), phenomenological mathematical modeling (Suzaki et al., 2017), Response Surface Methodology (Igberase et al., 2017; Kalantari et al., 2015) were used by researchers.

In this study, differently from the literature, waste orange peel was used as an adsorbent for Pd adsorption and the obtained results were modelled by different nonlinear mathematical methods (Polynomial, Smoothing Spline, Power, Exponential, Gaussian and Fourier curve fitting models). The results are discussed in two parts as kinetic model results and isotherm model results. Results of non-linear methods were compared to those of linear models (Langmuir, Freundlich, BET isotherms and pseudo first order, diffusion, pseudo second order kinetic models) that were already existed. Additionally, to evaluate the performance of all mathematical methods in terms of relation between estimated and observed data, least square curve fitting method was also applied.

\section{Material and Method}

In adsorption studies, waste orange peel was used as the adsorbent. First, the waste orange peels were washed, dried $\left(\right.$ at $55^{\circ} \mathrm{C}$ ), grinded and sieved to the particle size of 0.2 to $0.5 \mathrm{~mm}$. Pd standard solution was from Fluka in analytical purity.

\subsection{Experimental Studies}

Adsorption kinetics and isotherms experiments were realized for the conditions $\left(\mathrm{pH}: 5\right.$, temperature: $60^{\circ} \mathrm{C}$, duration:120 min.) that yield the highest Pd adsorption efficiency (92.77\% adsorption efficiency and $0.72 \mathrm{mgL}^{-1}$ final concentration) indicated in our previous study (Özkan et al., 2018). Adsorption experiments were realized with using $2.5 \mathrm{~g}$ of waste orange peel in the $500 \mathrm{~mL} \mathrm{Pd}$ solution at the initial concentration of $10 \mathrm{mgL}^{-1}$. For adsorption isotherm studies, different weights of waste orange peel $(0.05,0.1,0.2,0.3,0.4$ and $0.5 \mathrm{~g})$ were mixed with $500 \mathrm{~mL}$ of $10 \mathrm{mgL}^{-1} \mathrm{Pd}$ solution for $120 \mathrm{~min}$. Final palladium concentrations of the samples were measured by ICP-OES (Model 720, Varian, Palo Alto, CA, USA). According to the experimental results; pseudo first order, diffusion and pseudo second order models used for adsorption kinetics and Freundlich, Langmuir and BET isotherm models were applied. The detailed explanations were given in our previous study (Özkan et al., 2018). 


\subsection{Nonlinear Mathematical Fitting Models Application}

To model the Pd adsorption onto waste orange peel, six different nonlinear data modeling methods were applied: polynomial, smoothing spline, power, exponential, Gaussian and Fourier models. The polynomial model is explained in detail, including the basic approach of curve fitting, and other models are summarized. The details of the models can be found in the Chapra and Canale (2010). All of the models were implemented in MATLAB environment.

Polynomial Model: In order to reveal the mathematical procedure behind the curve fitting, the derivation of curve fitting with least square error minimization technique is exhibited by following stages. Assuming that we are aiming to modeling the data based on the second-order polynomial function with $\mathrm{a}_{0}, \mathrm{a}_{1}, \mathrm{a}_{2}$ coefficients. In this case, the mathematical model should be formulated as in Equation (1).

$$
e=y-a_{0}-a_{1} x-a_{2} x^{2}
$$

where e is the expected residual value. If the both of $y_{i}$ equations and then sum of squares of the residual (error) value are gathered and represented with a single equation as in Equation (2), then the curve fitting procedure can be initiated on given function.

$$
e_{\text {sum }}=\sum_{i=1}^{m}\left(y_{i}-a_{0}-a_{1} x-a_{2} x^{2}\right)^{2}
$$

With respect to the least square error minimization idea, it is required to take the derivative of both sides of equations per each coefficient stated on the fitted polynomial function as in Equation (3);

$$
\begin{aligned}
& \frac{\partial e_{\text {sum }}}{\partial a_{0}}=-2 \sum_{i=1}^{m}\left(y_{i}-a_{0}-a_{1} x_{\mathrm{i}}-a_{2} x_{\mathrm{i}}^{2}\right) \\
& \frac{\partial e_{\text {sum }}}{\partial a_{1}}=-2 \sum_{i=1}^{m} x_{i}\left(y_{i}-a_{0}-a_{1} x_{i}-a_{2} x_{i}^{2}\right) \\
& \frac{\partial e_{\text {sum }}}{\partial a_{2}}=-2 \sum_{i=1}^{m} x_{i}^{2}\left(y_{i}-a_{0}-a_{1} x_{i}-a_{2} x_{i}^{2}\right)
\end{aligned}
$$

Since the left side of equations was scalar, the derivative of scalar values would be simultaneously equal to zero. Also, the coefficient of summation symbols would be 1 , when the both side was divided with -2 . Later, the emergent each of terms can be arranged to expose the coefficients $\left(a_{0}, a_{1}, a_{2}\right)$ that are needed to be estimated as shown in Equation (4).

$$
\begin{aligned}
& {\left[\begin{array}{ccc}
m & \sum_{i=1}^{m} x_{i} & \sum_{i=1}^{m} x_{i}^{2} \\
\sum_{i=1}^{m} x_{i} & \sum_{i=1}^{m} x_{i}^{2} & \sum_{i=1}^{m} x_{i}^{3} \\
\sum_{i=1}^{m} x_{i}^{2} & \sum_{i=1}^{m} x_{i}^{3} & \sum_{i=1}^{m} x_{i}^{4}
\end{array}\right]\left[\begin{array}{l}
a_{0} \\
a_{1} \\
a_{2}
\end{array}\right]=\left[\begin{array}{c}
\sum_{i=1}^{m} y_{i} \\
\sum_{i=1}^{m} x_{i} y_{i} \\
\sum_{i=1}^{m} x_{i}^{2} y_{i}
\end{array}\right]} \\
& \underbrace{\text { Input Data }}_{X} \underbrace{\text { Coefficients }}_{A} \underbrace{\text { Observed Data }}_{Y}
\end{aligned}
$$

The obtained mathematical form refers a non-linear system. By expanding the idea of curve fitting, it can be easily adopt the concept of second-order curve fitting onto k th-order polynomial curve fitting as shown in Equation (5): 


$$
\left[\begin{array}{ccccc}
m & \sum_{i=1}^{m} x_{i} & \sum_{i=1}^{m} x_{i}^{2} & \ldots & \sum_{i=1}^{m} x_{i}^{k} \\
\sum_{i=1}^{m} x_{i} & \sum_{i=1}^{m} x_{i}^{2} & \sum_{i=1}^{m} x_{i}^{3} & \ldots & \sum_{i=1}^{m} x_{i}^{k+1} \\
\sum_{i=1}^{m} x_{i}^{2} & \sum_{i=1}^{m} x_{i}^{3} & \sum_{i=1}^{m} x_{i}^{4} & \ldots & \sum_{i=1}^{m} x_{i}^{k+2} \\
\vdots & \vdots & \vdots & & \vdots \\
\sum_{i=1}^{m} x_{i}^{k} & \sum_{i=1}^{m} x_{i}^{k+1} & \sum_{i=1}^{m} x_{i}^{k+2} & \ldots & \sum_{i=1}^{m} x_{i}^{k+k}
\end{array}\right]\left[\begin{array}{c}
a_{0} \\
a_{1} \\
a_{2} \\
\vdots \\
a_{k}
\end{array}\right]=\left[\begin{array}{c}
\sum_{i=1}^{m} y_{i} \\
\sum_{i=1}^{m} x_{i} y_{i} \\
\sum_{i=1}^{m} x_{i}^{2} y_{i} \\
\vdots \\
\sum_{i=1}^{m} x_{i}^{k} y_{i}
\end{array}\right]
$$

Smoothing Spline Model: Since the polynomial curve fitting is sensitive to trend of data, it yields a high error value when few terms chosen. On the other hand, if the high number of terms are chosen, then residual error becomes smaller, but the computational cost is increased with respect to selected number polynomial terms. To overcome these problems, a piecewise polynomial model, the smoothing spline curve fitting strategy were proposed as working based on the spline functions. Theoretically, a smoothing spline function with smoothing parameter was utilized in case of interpolation. Smoothing spline model minimizes the following error value as indicated in Equation (6).

$$
e_{\text {sum }}=p \sum_{i=1}^{n} w_{i}\left(y_{i}-s\left(x_{i}\right)\right)^{2}+(1-p) \int\left(\frac{d^{2} s}{d x^{2}}\right)^{2} d x
$$

Where, $w_{i}$ denotes the weight coefficient (default 1 ), $p$ is smoothing parameter between 0 and 1 as $p=0$ indicates a least-squares straight-line applied on data and $p=1$ denotes a cubic spline interpolant.

Power Model: Power curve fitting relies on describing the variation between two variables as power of another. In general, it is considered two independent variables are relatively dependent to each other. For example, the area of rectangle depends on the height and width, if the height and width are multiplied with 3 , then the area have to multiplied with 9, which is square of 3 . The one and two terms power function can be represented with Equation (7) and Equation (8), respectively.

$$
\begin{aligned}
& y=a x^{b} \\
& y=a x^{b}+c
\end{aligned}
$$

Where the $a, b$ and $c$ indicate the coefficients required to be estimated, while $\mathrm{x}$ and $\mathrm{y}$ refer to observed and estimated data, respectively.

Exponential Model: In addition to the power curve fitting as explained above, the exponential function can be used in terms of curve fitting based on the least square estimation. Let's assume that we want to represent the given original data with a one term exponential relationship equation likewise to Equation (9). In exponential case, an exponential function, e, is utilized on modeling function.

$$
y=a e^{b x}
$$

If one takes the logarithm of both sides of equation, then it will be in the form of Equation (10).

$$
\ln (y)=\ln \left(a e^{b x}\right)=\ln (a)+b x
$$

Later, the concept of least square error minimization applied to construct the augment matrix Equation (11).

$$
e_{\text {sum }}=\sum_{i=1}^{m}\left(\ln \left(y_{i}-a-b x_{i}\right)\right)^{2}
$$

To avoid giving great weights to $\mathrm{y}_{\mathrm{i}}$ values, the both side of equation is multiplied with and the derivation procedure applied on both side of equation. Once the derivation procedure completed, the formula would be turn out the following structure in Equation (12). 


$$
\left[\begin{array}{cc}
\sum_{i=1}^{m} y_{i} & \sum_{i=1}^{m} x_{i} y_{i} \\
\sum_{i=1}^{m} x_{i} y_{i} & \sum_{i=1}^{m} x_{i}^{2} y_{i}
\end{array}\right]\left[\begin{array}{l}
a \\
b
\end{array}\right]=\left[\begin{array}{c}
\sum_{i=1}^{m} y_{i} \ln y_{i} \\
\sum_{i=1}^{m} x_{i} y_{i} \ln y_{i}
\end{array}\right]
$$

Gaussian Model: The Gaussian curve fitting is another technique to summarize the characteristic of data with a Gaussian function. Similar to one term exponential, a Gaussian one term function is operated as shown in Equation (13). As if the least square estimation performed on the difference between estimated and original variable as given in Equation (14), then the model would be converted into augmented matrix form. The aim is determining the value of $a_{i}, b_{i}$ and $c_{i}$ coefficients.

$$
\begin{aligned}
& y_{i}=\sum_{i=1}^{m} a_{i} e^{\left[-\left(\frac{x_{i}-b_{i}}{c_{i}}\right)^{2}\right]} \\
& e_{\text {sum }}=\sum_{i=1}^{m}\left(y_{i}-a_{i} e^{\left[-\left(\frac{x_{i}-b_{i}}{c_{i}}\right)^{2}\right]}\right)^{2}
\end{aligned}
$$

Fourier Model: Based upon the Fourier assumption, it is possible to represent the data with a series of cosine and sine curves. The theory under Gaussian model was utilized in case of least square error estimation. Fourier model can be summarized with Equation (15).

$$
y=a_{0}+\sum_{i=1}^{n} a_{i}^{*} \cos (i w x)+b_{i}^{*} \sin (i w x)
$$

Where, $\mathrm{x}$ denotes the observed data, ao equals to model constant as taking $\mathrm{i}=0$, w refers to frequency of observed data and $\mathrm{n}$ is the number of terms for modeling the data.

\subsection{Performance Evaluation Metrics}

To evaluate the performance of proposed methods, some statistical metrics were utilized to reveal the relation between estimated and observed data. The observed data refers to experimental amount of adsorbed Pd by the waste orange peels, whereas the estimated data indicate the data points obtained after applied mathematical curve fitting functions. Depending upon the error metrics, the results of linear and non-linear regression models for kinetic and isotherm studies were compared to each other in terms of benchmarking performance evaluation. Specifically, the produced lowest error value from a model presents the best fitting one in terms of making some predictions on adsorbed Pd concentrations onto orange peels.

For statistical performance evaluation, the R-square $\left(\mathrm{R}^{2}\right)$, Sum of Square (SSE) and Root Mean Square Error (RMSE) numerical metrics were utilized. Technically, the obtained lower value of SSE and RMSE refers to the more accurate modelled the data. SSE indicates the sum of squares of residuals between estimated and observed palladium concentrations. In a simple way, the SSE is computed with Equation (16).

$$
\mathrm{SSE}=\sum_{\mathrm{i}=1}^{\mathrm{n}}\left(\mathrm{X}_{\text {observed,i }}-\mathrm{X}_{\text {estimated,i }}\right)^{2}
$$

As n refers to number of observations $\mathrm{X}_{\mathrm{observed}, \mathrm{i}}$ and $\mathrm{X}_{\mathrm{estimated}, \mathrm{i}}$ denote the $\mathrm{i}$. value of estimated and measured data for palladium, respectively. On the other side, the RMSE unveils the squared root of mean square error (MSE). RMSE can be obtained as represented with Equation (17).

$$
\mathrm{RMSE}=\sqrt{\mathrm{MSE}}, \mathrm{MSE}=\mathrm{SSE} / \mathrm{n}
$$

where $\mathrm{n}$ is the number of observations. For the performance evaluation, we would like to expect that the value of SSE and RMSE should be more close to 0 , and the value of $\mathrm{R}^{2}$ should be high as much as possible, in terms of good accuracy rate.

$\mathrm{R}^{2}$ is the coefficient of determination and is computed with Equation (18). 


$$
\mathrm{SST}=\sum_{\mathrm{i}=1}^{\mathrm{n}}\left(\text { estimated }_{\mathrm{i}}-\overline{\mathrm{x}}\right), \mathrm{R}^{2}=1-\frac{\mathrm{SSE}}{\mathrm{SST}}
$$

In given Equation (18), SST denotes the total sum of square error and $\bar{x}$ refers to mean of observed data.

\section{Results and Discussions}

The results are discussed in two parts as kinetic model and isotherm model results.

\subsection{Kinetic Model Results}

Likewise, the aforementioned curve fitting models were applied on kinetic coefficients. The visual plots of each nonlinear model with linked $\mathrm{R}^{2}$ scores are given in Figure 1 ( $\mathrm{t}$ : min; qt: mg/g). According to Figure 1, the best fitted nonlinear models are Smoothing Spline and Gaussian models show the best fitting ( $\left.\mathrm{R}^{2}: 1\right)$ fluctuations with increased time intervals.

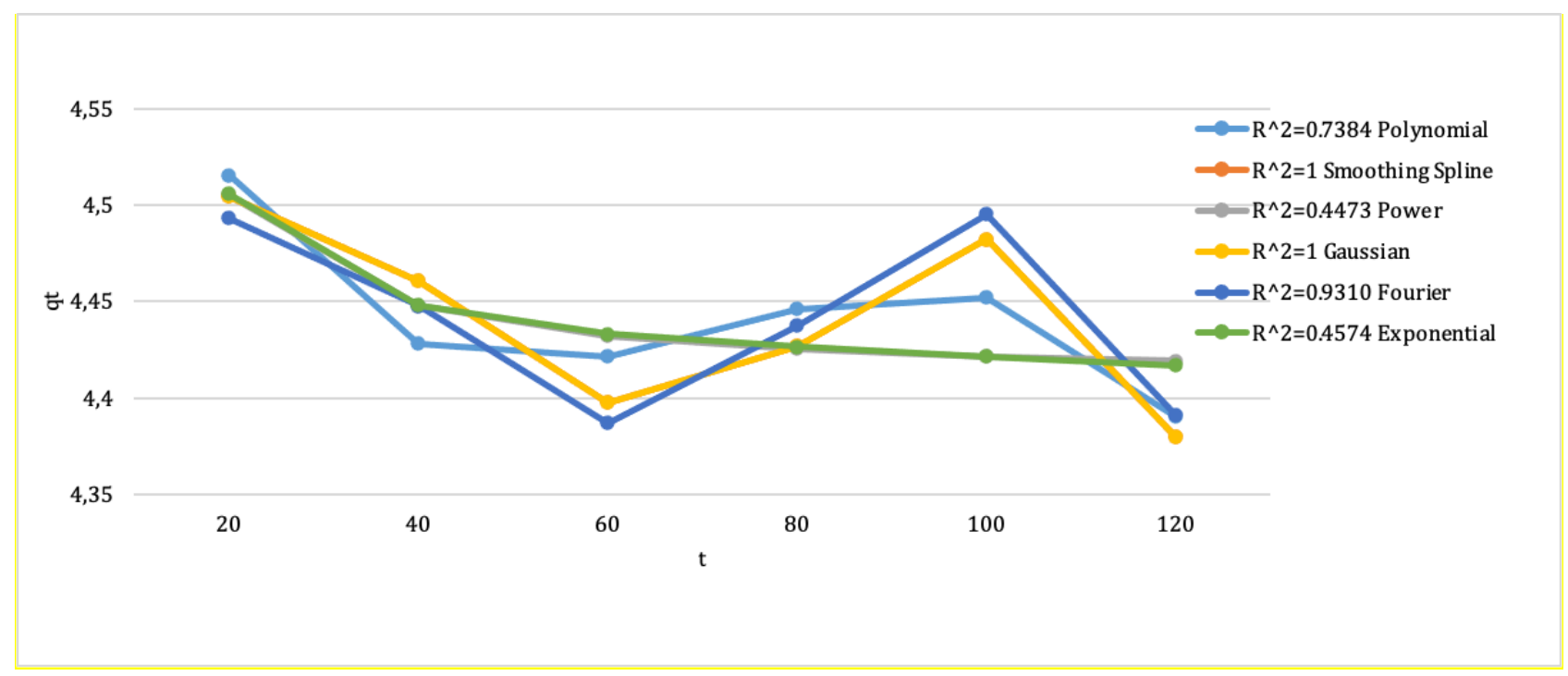

Figure 1. Fitting graphics of nonlinear models for kinetic studies

In addition to Figure 1, Table 1 represents results of statistical metrics for linear (pseudo first order, pseudo second order and diffusion models) and nonlinear models (polynomial, smoothing spline, power, exponential, Gaussian and Fourier models). Undoubtedly, it can be inferred that the pseudo second order model presents dominant $\mathrm{R}^{2}$ value, which is reported as $\mathbf{0 . 9 9 9 5}$. On the other side, the performances of pseudo first order model and diffusion model are very similar to each other. Although the higher value of $\mathrm{R}^{2}$ obtained in case of pseudo second order model, but the SSE and RMSE scores are not satisfied in terms of describing the characteristic of data when comparing with other kinetic models. Based on this fact, it is vitally important to emphasize that it would be not correct to decide whether a fitted mathematical model is efficient and promising only by considering $\mathrm{R}^{2}$ values. Therefore, the SSE and RMSE values should be taking into account as well as $\mathrm{R}^{2}$. According to Table 1 , for nonlinear models, Gaussian (two terms), smoothing spline and pseudo second order model were very close to each other. Although the higher value of $\mathrm{R}^{2}$ obtained in case of pseudo second order model, but the SSE and RMSE scores are not satisfied in terms of describing the characteristic of data when comparing with other kinetic models. Then it can be said that the Gaussian and Smoothing spline are in a competition and produced same results that are superior to kinetic and other curve fitting models. In fact, the sharp differential in performance can be distinguished when the RMSE values are taken as reference. Clearly, it is shown that the Smoothing spline model take first place in ranking with 0.0000 score, whereas the Gaussian model comes in second rank with 0.0028 score in terms RMSE metric. 
Table 1. The statistical performance of linear and nonlinear models for kinetic studies

\begin{tabular}{|c|c|c|c|c|}
\hline Model & $\mathbf{R}^{2}$ & SSE & RMSE & Function \\
\hline \multicolumn{5}{|l|}{ Linear Models } \\
\hline Pseudo first order & 0.3364 & 0.0079 & 0.0445 & $y=0.0008 x+0.0095$ \\
\hline Pseudo second order & 0.9995 & 0.1634 & 0.2021 & $y=0.2275 x-0.1201$ \\
\hline Diffusion Model & 0.3722 & 0.0075 & 0.0433 & $y=-0.0124 x+4.542$ \\
\hline \multicolumn{5}{|l|}{ Nonlinear Models } \\
\hline $\begin{array}{l}\text { Polynomial } \\
\text { (two terms) }\end{array}$ & 0.3684 & 0.0075 & 0.0501 & $\begin{array}{c}\mathrm{y}=\mathrm{p} 1 * \mathrm{x}^{\wedge} 2+\mathrm{p} 2 * \mathrm{x}+\mathrm{p} 3 \\
\mathrm{p} 1=0.1151, \mathrm{p} 2=-0.2252, \mathrm{p} 3=4.5250\end{array}$ \\
\hline $\begin{array}{l}\text { Polynomial } \\
\text { (three terms) }\end{array}$ & 0.7384 & 0.0031 & 0.0395 & $\begin{array}{c}y=p 1^{*} x^{\wedge} 3+p 2^{*} x^{\wedge} 2+p 3^{*} x+p 4 \\
p 1=-1.032 e-06, p 2=0.0002247, p 3=-0.01496, p 4=4.733\end{array}$ \\
\hline Smoothing Spline & 1 & 0.0000 & 0.0000 & $\begin{array}{l}\mathrm{y}=\text { piecewise polynomial computed from } \mathrm{p} \\
\mathrm{p}=0.999986\end{array}$ \\
\hline $\begin{array}{c}\text { Power } \\
\text { (two terms) }\end{array}$ & 0.4473 & 0.0066 & 0.0469 & $\begin{array}{c}\mathrm{y}=\mathrm{a}^{*} \mathrm{x}^{\wedge} \mathrm{b}+\mathrm{c} \\
\mathrm{a}=5.516, \mathrm{~b}=-1.359, \mathrm{c}=4.411\end{array}$ \\
\hline $\begin{array}{l}\text { Exponential } \\
\text { (two terms) }\end{array}$ & 0.4574 & 0.0065 & 0.0569 & $\begin{array}{c}y=a^{*} \exp \left(b^{*} x\right)+c^{*} \exp \left(d^{*} x\right) \\
a=0.3442, b=-0.08291, c=4.445, d=-5.265 e-05\end{array}$ \\
\hline $\begin{array}{c}\text { Gaussian } \\
\text { (two terms) }\end{array}$ & 1 & 0.0000 & 0.0028 & $\begin{array}{c}\mathrm{y}=\mathrm{a} 1^{*} \exp \left(-((\mathrm{x}-\mathrm{b} 1) / \mathrm{c} 1)^{\wedge} 2\right)+\mathrm{a} 2^{*} \exp \left(-((\mathrm{x}-\mathrm{b} 2) / \mathrm{c} 2)^{\wedge} 2\right. \\
\mathrm{a} 1=3.966, \mathrm{~b} 1=1.858, \mathrm{c} 1=76.98, \mathrm{a} 2=4.007, \mathrm{~b} 2=122.3, \mathrm{c} 2=79.08\end{array}$ \\
\hline $\begin{array}{c}\text { Fourier } \\
\text { (Two terms) }\end{array}$ & 0.9310 & 0.0008 & 0.0287 & $\begin{array}{c}\mathrm{y}=\mathrm{a} 0+\mathrm{a} 1 * \cos \left(\mathrm{x}^{*} \mathrm{w}\right)+\mathrm{b} 1 * \sin \left(\mathrm{x}^{*} \mathrm{w}\right)+\mathrm{a} 2 * \cos \left(2^{*} \mathrm{x}^{*} \mathrm{w}\right)+\mathrm{b} 2 * \sin \left(2^{*} \mathrm{x}^{*} \mathrm{w}\right) \\
\mathrm{a} 0=4.435, \mathrm{a} 1=-0.09568, \mathrm{~b} 1=0.01781, \mathrm{a} 2=0.0349, \mathrm{~b} 2=- \\
0.03441, \mathrm{w}=0.09959\end{array}$ \\
\hline
\end{tabular}

Table 2 shows that, although Gaussian and Smooting Spline methods were determined as the best fitting models by this study, generally the highest $\mathrm{R}^{2}$ values $(>0.99)$ in the literature studies are obtained by pseudo-secondorder models.

Table 2. Comparison of the adsorption kinetic results with the literature

\begin{tabular}{llll}
\hline Reference & Adsorbent & Model type & $\mathbf{R}^{2}$ \\
\hline \multirow{3}{*}{ Omidinasab et al., 2018 } & Pseudo first order & 0.933 \\
& magnetic chitosan & Pseudo second order & 0.9989 \\
& nanoparticles & Elovich & 0.7288 \\
& & Intra particle diffusion & 0.577 \\
\hline \multirow{2}{*}{ Shafizadeh et al., 2019 } & magnetic ion-imprinted & Pseudo first order & 0.987 \\
& polymer & Pseudo second order & 0.999 \\
\hline \multirow{2}{*}{ Sato et al., 2019 } & \multirow{2}{*}{ Silk fibroin fiber } & Pseudo first order & 0.8275 \\
& & Pseudo second order & 0.9964 \\
& \multirow{2}{*}{ PEI-chitin } & Intra particle diffusion & 0.6642 \\
\hline \multirow{2}{*}{ Wang et al., 2021 } & & Pseudo first order & 0.992 \\
& Amberjet 4200 & Pseudo second order & 0.989 \\
& & Pseudo first order & 0.999 \\
& SYL-0830 & Pseudo second order & 0.978 \\
Özkan et al., 2018 (Our & \multirow{2}{*}{ Waste orange peel } & Pseudo first order & 0.861 \\
previous study) & & Pseudo second order & 0.916 \\
\hline \multirow{2}{*}{ This study } & Pseudo first order & 0.5966 \\
& & Pseudo second order & 0.9995 \\
& & Gaussian and Smooting & 0.3722 \\
\hline
\end{tabular}

\subsection{Isotherm Model Results}

While the trend behind coefficients of isotherms is represented with linear functions, the curve fitting methods are modelled based on the non-linear functions obtained based on the least square error minimization procedure. The low value of SSE and RMSE with high value of $\mathrm{R}^{2}$ imply the efficient curve fitting model in terms of either summarizing the relationship between coefficients or predicting the unknown inter values with respect to fitted model. The visual analysis of results obtained by utilized mathematical curve fitting functions is given in Figure 2 . Table 3 reflects the statistical performance results produced by linear and nonlinear models. Comparing the $\mathrm{R}^{2}$ coefficient among the isotherms it can observed that BET model yields a better fit than Langmuir and Freundlich isotherms. Upon inspecting the results, the performance of Freundlich isotherm was outperformed Langmuir isotherm. The observed considerable increase in performance of Freundlich isotherm can be explained that constructing mathematical models on normalized values makes model more resistance to outliers, which always ruin the common trend behind the processed data and widely accepted as noisy values. From this aspect, one can 
emphasize that the performance gradually increases in case of taking the logarithmic values of isotherm's coefficients including the $\mathrm{Ce}$ and qe. Thus, the normalization process makes data more smoothing form even if the noise existed. By observing the results given Table 3, it can be said that lowest SSE value of isotherms is reported to 0.0012 in case of Langmuir isotherm while the SSE values of Freundlich and BET isotherms are reported to 0.2112 and 231.1674, respectively. Also, similar outputs can be observed when RMSE values are ground on. If both the SSE and RMSE error results with $\mathrm{R}^{2}$ values are considered together, it is able to deduce that Langmuir isotherm is better than Freundlich and BET isotherms in terms of prevailing the trend of data. Also, comparison of the adsorption isotherm results with the literature is given in Table 4. According to the table, in the nonlinear model in this study, higher $\mathrm{R}^{2}$ value was obtained than linear models in the literature.

As, it can be observed from Table 3 and Figure 2, that best $\mathrm{R}^{2}$ is noted as 0.9903 by smoothing spline curve fitting model with the lowest SSE value of 0.0265 . When compared to isotherms models, it can be seen that $\mathrm{R}^{2}$ of smoothing spline model is higher than those of BET isotherm model ( $\mathrm{R}^{2}:$ 0.9798). On the other hand, the second rank of performance is obtained by Polynomial model ( $\left.\mathrm{R}^{2}: 0.9879\right)$. Although the good result of $\mathrm{R}^{2}$ and low value of SSE are generated by smoothing spline, it can be apparently seen that the performance of polynomial (threeterms) is favorable when the lowest error value reported to 0.1335 is considered.

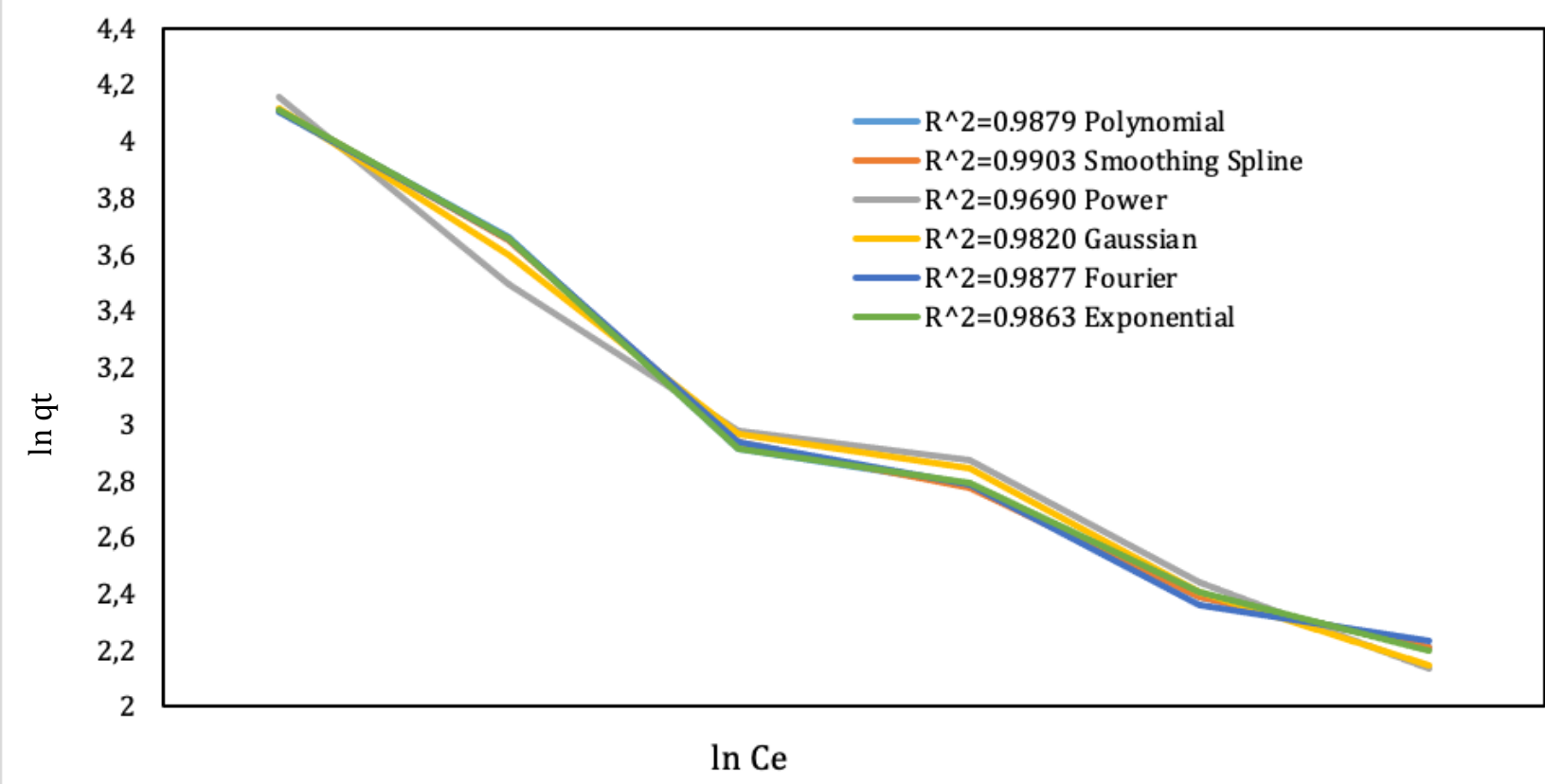

Figure 2. Fitting graphics of nonlinear models for isotherm studies

Table 3. The statistical performance of linear and nonlinear models for isotherm studies

\begin{tabular}{|c|c|c|c|c|}
\hline Models & $\mathbf{R}^{2}$ & SSE & RMSE & Function \\
\hline \multicolumn{5}{|l|}{ Linear Models } \\
\hline $\begin{array}{r}\text { Langmuir } \\
\text { isotherm }\end{array}$ & 0.8234 & 0.0012 & $\begin{array}{c}0.017 \\
2\end{array}$ & $y=2.1048 x-0.3107$ \\
\hline $\begin{array}{r}\text { Freundlich } \\
\text { isotherm }\end{array}$ & 0.9229 & 0.2112 & $\begin{array}{c}0.229 \\
8 \\
\end{array}$ & $y=7.6252 x-10.255$ \\
\hline $\begin{array}{r}\text { BET } \\
\text { isotherm }\end{array}$ & 0.9798 & $\begin{array}{c}231.16 \\
7 \\
\end{array}$ & $\begin{array}{c}7.602 \\
1 \\
\end{array}$ & $y=831.83 x-442.74$ \\
\hline \multicolumn{5}{|l|}{ Nonlinear Models } \\
\hline $\begin{array}{r}\text { Polynomial } \\
\text { (three terms) }\end{array}$ & 0.9879 & 0.0356 & $\begin{array}{c}0.133 \\
5\end{array}$ & $\begin{array}{c}y=p 1^{*} x^{\wedge} 3+p 2^{*} x^{\wedge} 2+p 3^{*} x+p 4 \\
p 1=-244.6, p 2=1276, p 3=-2207, p 4=1268\end{array}$ \\
\hline $\begin{array}{r}\text { Smoothing Spline } \\
\text { (two terms) }\end{array}$ & 0.9903 & 0.0265 & $\begin{array}{c}0.135 \\
8\end{array}$ & $\begin{array}{l}\mathrm{y}=\text { piecewise polynomial computed from } \mathrm{p} \\
\mathrm{p}=0.999998\end{array}$ \\
\hline
\end{tabular}


Table 3. Continued

\begin{tabular}{|c|c|c|c|c|}
\hline $\begin{array}{r}\text { Power } \\
\text { (two terms) }\end{array}$ & 0.9690 & 0.0851 & $\begin{array}{c}0.168 \\
4\end{array}$ & $\begin{array}{c}y=a^{*} x^{\wedge} b+c \\
a=-209.6, b=-8.585, c=4.975\end{array}$ \\
\hline $\begin{array}{l}\text { Exponential } \\
\text { (two terms) }\end{array}$ & 0.9863 & 0.0376 & $\begin{array}{c}0.137 \\
2\end{array}$ & $\begin{array}{c}y=a^{*} \exp \left(b^{*} x\right)+c^{*} \exp \left(d^{*} x\right) \\
a=-5.478 \mathrm{e}-17, b=20.12, c=0.001922, d=4.27\end{array}$ \\
\hline $\begin{array}{r}\text { Gaussian } \\
\text { (two terms) }\end{array}$ & 0.9820 & 0.0495 & $\begin{array}{c}0.222 \\
4\end{array}$ & $\begin{array}{c}\mathrm{y}=\mathrm{a} 1 * \exp \left(-((\mathrm{x}-\mathrm{b} 1) / \mathrm{c} 1)^{\wedge} 2\right)+\mathrm{a} 2 * \exp \left(-((\mathrm{x}-\mathrm{b} 2) / \mathrm{c} 2)^{\wedge} 2\right. \\
\mathrm{a} 1=0, \mathrm{~b} 1=12.15, \mathrm{c} 1=1.211, \mathrm{a} 2=4.128, \mathrm{~b} 2=1.891, \mathrm{c} 2=0.2974\end{array}$ \\
\hline $\begin{array}{r}\text { Fourier } \\
\text { (two terms) }\end{array}$ & 0.9877 & 0.0336 & $\begin{array}{l}0.183 \\
3\end{array}$ & $\begin{array}{c}y=a 0+a 1 * \cos \left(x^{*} w\right)+b 1 * \sin \left(x^{*} w\right)+a 2 * \cos \left(2 * x^{*} w\right)+b 2 * \sin \left(2 * x^{*}\right. \\
w) \\
a 0=3.468 a 1=-0.6309, b 1=-0.7221, a 2=-0.1642, b 2=- \\
0.2769 w=11.89\end{array}$ \\
\hline
\end{tabular}

Table 4. Comparison of the adsorption isotherm results with the literature

\begin{tabular}{llll}
\hline Reference & Adsorbent & Model type & $\mathrm{R}^{2}$ \\
\hline \multirow{3}{*}{ Omidinasab et al., 2018 } & & Langmuir & 0.8882 \\
& magnetic chitosan & Freundlich & 0.9805 \\
& nanoparticles & Temkin & 0.85 \\
& & Dubinin-Radushkevich & 0.7949 \\
\hline \multirow{2}{*}{ Shafizadeh et al., 2019 } & magnetic ion- & Langmuir & 0.989 \\
& imprinted polymer & Freundlich & 0.965 \\
\hline \multirow{2}{*}{ Sato et al., 2019 } & \multirow{2}{*}{ Silk fibroin fiber } & Langmuir & 0.9755 \\
& \multirow{2}{*}{ PEI-chitin } & Freundlich & 0.9557 \\
\hline \multirow{2}{*}{ Wang et al., 2021 } & \multirow{2}{*}{ Amberjet 4200 } & Langmuir & 0.944 \\
& & Lreundlich & 0.858 \\
& \multirow{2}{*}{ SYL-0830 } & Freundlich & 0.987 \\
\multirow{2}{*}{$\begin{array}{l}\text { Özkan et al., 2017 (Our } \\
\text { previous study) }\end{array}$} & \multirow{2}{*}{ Waste orange peel } & Langmuir & 0.906 \\
& & Freundlich & 0.935 \\
\multirow{2}{*}{ This study } & \multirow{2}{*}{ Waste orange peel } & Freundlich & 0.970 \\
\hline
\end{tabular}

\section{Conclusion}

In this study, different nonlinear curve fitting models applied to experimental kinetic and isotherms data of Pd adsorption onto waste orange peel. Additionally, different linear models were also applied to kinetic studies. Results obtained from linear and non-linear regression methods were compared to determine the best fitting of isotherm and kinetic model to experimental data. Based on this fact, it is vitally important to emphasize that it would be not correct to decide whether a fitted mathematical model is efficient and promising only by considering $\mathrm{R}^{2}$ values. Therefore, the SSE and RMSE values should be taking into account as well as $\mathrm{R}^{2}$. According to results, Smoothing Spline model shows best fitting with higher $\mathrm{R}^{2}$ and lower SSE and RMSE values. Results indicate that using the curve fitting is not only efficient, but also an effortless process in terms of estimating the amount of adsorbed Pd with respect to varied amount of orange peels. As a further study, modeling equations would be applied to different metal adsorption studies.

\section{Acknowledgement}

This study was supported by the Anadolu University Scientific Research Projects Commission under grant no: $1503 F 143$.

\section{Conflict of Interest}

No conflict of interest was declared by the authors.

\section{References}

Adhikari, C.R., Parajuli, D., Kawakita, H., Inoue, K., Ohto, K., Harada, H., 2008. Dimethylamine-modified waste paper for the recovery of precious metals. Environmental Science and Technology, 42(15). 5486-5491.

Chapra, S. C., Canale, R. P., 2010. Numerical methods for engineers. Boston: McGraw-Hill Higher Education.

Fabre, E., Lopes, C.B., Vale, C., Pereira, E., Silva, C.M., 2020. Valuation of banana peels as an effective biosorbent for mercury removal under low environmental concentrations. Science of the Total Environment, 709, 135883. 
Fayemi, O.E., Adeniyi, S.O., Kempgens, P.F.M., Antunes, E., Torto, N., Nyokong, T., Tshentu, Z.R., 2013. Adsorption and separation of platinum and palladium by polyamine functionalized polystyrene-based beads and nanofibers. Mineral Engineering, 53 , 256-265.

Herrero, R., Lodeiro, P., García-Casal, L.J., Vilariño, T., Rey-Castro, C., David, C., Rodríguez, P., 2011. Full description of copper uptake by algal biomass combining an equilibrium NICA model with a kinetic intraparticle diffusion driving force approach. Bioresource Technology, 102 (3), 2990-2997.

Igberase, E., Osifo, P., Ofomaja, A., 2017, Chromium (VI) ion adsorption by grafted cross-linked chitosan beads in aqueous solution-a mathematical and statistical modeling study. Environmental Technology, 38(24), 3156-3166.

Kalantari, K., Ahmad, M.B., Masoumi, H.R., Shameli, K., Basri, M., Khandanlou, R., 2015, Rapid and high capacity adsorption of heavy metals by Fe304/montmorillonite nanocomposite using response surface methodology: preparation, characterization, optimization, equilibrium isotherms, and adsorption kinetics study. Journal of Taiwan Institute of Chemical Engineers, 49, 192-198.

Kızmaz, A., Altıok, D., Barutçu Mazı, I., 2019. Adsorption Isotherms of Kiwifruit Dried By Different Drying Methods, Mühendislik Bilimleri ve Tasarım Dergisi, 7(1), 167-174.

Morcali, M.H., Zeytuncu, B., 2015. Investigation of adsorption parameters for platinum and palladium onto a modified polyacrylonitrile-based sorbent. International Journal of Mineral Processing, 137, 52-58.

Omidinasab, M., Rahbar, N., Ahmadi, M., Kakavandi, B., Ghanbari, F., Kyzas, G.Z., Martinez, S.S. \& Jaafarzadeh, N. 2018. Removal of vanadium and palladium ions by adsorption onto magnetic chitosan nanoparticles. Environmental Science and Pollution Research, 25(34), 34262-34276.

Özkan, A., Günkaya, Z., Yapıcı, E., Banar, M., 2018. Palladium Adsorption from Printed Circuit Boards with Waste Orange Peels. Süleyman Demirel Üniversitesi Fen Bilimleri Enstitüsü Dergisi, 22(1), 201-206.

Öztürk, M., Yıldız, S., Aslan, Ș., 2020. Nikel (II) İyonlarının Atık Çay’a Biyosorpsiyonu: Denge, Kinetik ve Termodinamik Çalışmaları. Mühendislik Bilimleri ve Tasarım Dergisi, 8(4), 985-998.

Parajuli, D., Khunathai, K., Adhikari, C.R., Inoue, K., Ohto, K., Kawakita, H., Funaoka, M., Hirota, K., 2009. Total recovery of gold, palladium, and platinum using lignophenol derivative. Mineral Engineering, 22, 1173-1178.

Putri, K.N.A., Keereerak, A., Chinpa, W., 2020. Novel cellulose-based biosorbent from lemongrass leaf combined with cellulose acetate for adsorption of crystal violet. International Journal of Biologica Macromolecules, 156, 762-772.

Rathinam, A., Maharshi, B., Janardhanan, S.K., Jonnalagadda, R.R., Nair, B.U., 2010. Biosorption of cadmium metal ion from simulated wastewaters using Hypnea valentiae biomass: A kinetic and thermodynamic study. Bioresource Technology, 101(5), 1466-1470

Sato, T., Abe, S., Ito, S., Abe, T. 2019. Silk fibroin fiber for selective palladium adsorption: Kinetic, isothermal and thermodynamic properties. Journal of Environmental Chemical Engineering, 7(2), 102958.

Sayın, M., Can, M., Imamoğlu, M., Arslan, M., 2015. 1,3,5-Triazine-pentaethylenehexamine polymer for the adsorption of palladium (II) from chloride-containing solutions. Reactive and Functional Polymers, 88, 31-38.

Shafizadeh, F., Taghizadeh, M., Hassanpour, S., 2019. Preparation of a novel magnetic Pd(II) ion-imprinted polymer for the fast and selective adsorption of palladium ions from aqueous solutions. Environmental Science and Pollution Research, 26, $18493-18508$

Sharma, S., Rajesh, N., 2016. Augmenting the adsorption of palladium from spent catalyst using a thiazole ligand tethered on an amine functionalized polymeric resin. Chemical Engineering Journal, 283, 999-1008.

Sharma, A., Rajesh, N., 2014. 2-Mercaptobenzothiazole impregnated cellulose prepared by ultrasonication for the effective adsorption of precious metal palladium. Chemical Engineering Journal, 241, 112-121.

Suzaki, P.Y.R., Munaro, M.T., Triques, C.C., Kleinübing, S.J., Klen, M.R.F., de Matos Jorge, L.M., Bergamasco, R., 2017. Biosorption of binary heavy metal systems: Phenomenological mathematical modeling. Chemical Engineering Journal, 313, $364-373$.

Tunç Dede, Ö. 2019. Potential Use of Hazelnut Processing Plant Wastes as a Sorbent for the Simultaneous Removal of MultiElements From Water. Mühendislik Bilimleri ve Tasarım Dergisi, 7(2), 301-302.

Wang, Z., Kang, S.B., Won, S.W., 2021. Selective adsorption of palladium(II) from aqueous solution using epichlorohydrin crosslinked polyethylenimine-chitin adsorbent: Batch and column studies. Journal of Environmental Chemical Engineering, 9(2), 105058.

Yang, Y., Lin, X., Wei, B., Zhao, Y., Wang, J., 2014. Evaluation of adsorption potential of bamboo biochar for metal-complex dye: equilibrium, kinetics and artificial neural network modeling. International Journal of Environmental Science and Technology, 11(4), 1093-1100. 